\title{
Influencing Factors and Quality Evaluation of Urban Thermal Environment Based on Artificial Neural Network
}

\author{
Liangwei Zhao ${ }^{1 *}$, Xiaowei $\mathrm{Li}^{2}$, Xuguang Chai ${ }^{3}$ \\ ${ }^{1}$ Science and Technology Development Center, Xingtai Polytechnic College, Xingtai 054035, China \\ ${ }^{2}$ Automobile Engineering Department, Xingtai Polytechnic College, Xingtai 054035, China \\ ${ }^{3}$ Information Engineering Department, Xingtai Polytechnic College, Xingtai 054035, China
}

Corresponding Author Email: zlwgongzuo@126.com

https://doi.org/10.18280/ijht.390113

Received: 8 August 2020

Accepted: 30 November 2020

\section{Keywords:}

neural network, urban thermal environment, quality evaluation, urban heat island effect

\begin{abstract}
To alleviate the urban heat island effect that is getting increasingly serious these days, the research on the monitoring, simulation, and regulation of the thermal environment of cities has become a necessity. Aiming at figuring out the correlations between influencing factors and giving accurate quality evaluation of urban thermal environment, this study extracted 10 influencing factors of urban thermal environment and gave their influence, and then performed the Land Surface Temperature (LST) retrieval of a target city. After that, this paper constructed a Multiple Linear Regression (MLR) model and explored the law of the numerical changes of the influencing factors of urban thermal environment. At last, this paper also built a BP neural network to predict the quality evaluation of urban thermal environment and used experimental results to prove the effectiveness of the proposed algorithm and model.
\end{abstract}

\section{INTRODUCTION}

With the progress of urbanization, the state of urban land utilization and the landscape patterns are changing constantly, green vegetation is gradually reducing while artificial architectures are growing and the roads and streets are becoming increasingly denser. All these situations have led to the increase in the temperature in central urban districts, and the deterioration of ecological environment in cities has become an unstoppable trend [1-3]. The urban heat island effect, which has a direct impact on the thermal comfort of human body and the efficiency of industrial production, has become a common problem for large and medium-sized cities in China [4-7]. Carrying out studies on the monitoring, simulation, and regulation of the thermal environment of cities can effectively alleviate the increasingly serious urban heat island effect, help reduce energy consumption, prevent environmental pollution, and improve living conditions [8-11].

To figure out the relationship between urban thermal effect and land utilization pattern in the process of urbanization, scholars Takebayashi and Moriyama [12] used remote sensing data to comparatively analyze the land utilization pattern and the LST of Wu'an City Hebei Province in 2001 and 2015; then based on the obtained type maps and retrieval graphs, the change trend was analyzed and the landscape pattern index under the dynamic response of thermal environment was calculated. To optimize urban planning and improve ecological environment, scholars Howard N. Bianca and Modi Vijay applied the methods of spatio-temporal data fusion and time series decomposition to conduct qualitative and quantitative research on LST. Based on the ESTARFM fusion algorithm, the surface temperature time series with a fixed time scale were obtained, and the BFAST algorithm was employed to decompose the average temperature series of the construction land, green space, rivers, and lakes in the central urban district; finally, the urban "hot spots" within the upper and lower downtown areas were extracted. Figuring out the spatial heterogeneity and distribution of thermal environment is of great significance for promoting sustainable urban development and mitigating the urban heat island effect [1316]. Scholars Palou and Mahalov [17] adopted a shadow height method and a single-window algorithm to extract and calculate the urban building height and LST; in their study, greenbelt patch and building patch were selected as the surface factors with the cooling effect and the heating effect, then through experiment, the results of the impact of urban construction land utilization regulation on temperature under different scales were obtained. Existing studies concerning the modeling of urban energy consumption generally lack the consideration of the dynamic man-made heat emission. Therefore, later on, Chatterjee et al. [18] updated and improved the existing models and realized the simulation of the indoor-outdoor heat transfer and exchange process of urban buildings with the dynamic man-made heat emission taken into consideration; the constructed energy balance equation and the estimated temperature field parameters were more accurate and complete; then, with a medium-sized city as an example, the city's thermal environment evolution in the process of urbanization was quantitatively analyzed. Since there are often contradictions between the time and space resolution of high-resolution remote sensing images [19-22], in response to this problem, Malings et al. [23] proposed an urban-space downscaling thermal environment analysis method, and achieved LST retrieval and space downscaling based on the radiation transfer equation method and the Distrad algorithm; and they used actual examples to analyze the change trend of LST in the city under the influence of temporal and spatial changes of underlying surface in the past 
5 years. Sabatino et al. [24] analyzed the spatial distribution characteristics of abnormal urban thermal blocks based on the results of LST retrieval; by comparing the boundary of builtup areas and the boundary of thermal environment areas, it was found that the two were basically consistent; after that, they employed MLR to conduct correlation analysis on the LST of areas with different land utilization patterns, and finally proposed a quantitative method for mitigating the thermal abnormalities of high-temperature blocks. Starting from the perspective of urban forest coverage, Guo et al. [25] explored the relationship between urban greening, ecological environment treatment, and urban thermal environment from two aspects of forest patch features and greenbelt patterns; then, through an analysis on the spotty distribution pattern of moderate temperature, sub-high temperature, and ultra-high temperature patches, they obtained the evolution trend of urban heat island effect, and proposed a few forest coverage optimization strategies for the optimization of urban thermal environment.

To sum up, in existing literatures, the analysis on the influencing factors of urban thermal environment is not systematic enough; they mostly focus on only one aspect such as the construction of urban energy models, the LST retrieval, or the identification of thermal environment patterns, few of them has concerned about the correlation between influencing factors, and now there isn't an effective method to evaluate the quality of urban thermal environment. To this end, in the second chapter, this paper extracted 10 influencing factors of urban thermal environment and gave their influence, and then performed LST retrieval of a target city based on the L1B data of MODIS (Moderate-resolution imaging spectroradiometer). The third chapter constructed the MLR model and explored the law of the numerical change of the influencing factors of urban thermal environment. The fourth chapter built a BP neural network to predict the quality evaluation of urban thermal environment, and the fifth chapter used experimental results to prove the effectiveness of the proposed algorithm and model.

\section{INFLUENCING FACTORS OF URBAN THERMAL ENVIRONMENT AND MEASUREMENT OF LST}

To figure out the impact of urban planning and land attribute on urban thermal environment, this paper extracted 10 influencing factors that are related to urban planning characteristics. Table 1 lists the influencing factors and their influence. According to the table, the influencing factors of urban planning mainly include five items: land utilization scale, building density, gross floor area density of building, greenbelt area, and average number of floors; and the influencing factors of land attribute also includes five items: location, water vapor content of atmosphere, greenbelt area of surrounding areas, building density of surrounding areas, gross floor area density of building of surrounding areas.

Table 1. Influencing factors of urban thermal environment and their influence

\begin{tabular}{|c|c|c|c|c|}
\hline Type & Code & Name & Influence & Data source \\
\hline \multirow{5}{*}{$\begin{array}{l}\text { Influencing } \\
\text { factors of } \\
\text { urban } \\
\text { planning }\end{array}$} & $F A_{1}$ & Land utilization scale & $\begin{array}{l}\text { This factor will affect the surface heat } \\
\text { distribution in the city }\end{array}$ & $\begin{array}{c}\text { Statistics, measurement, } \\
\text { calculation }\end{array}$ \\
\hline & $F A_{2}$ & Building density & $\begin{array}{c}\text { This factor will affect the heat dissipation per unit } \\
\text { area of land }\end{array}$ & $\begin{array}{l}\text { Statistics, measurement, } \\
\text { calculation }\end{array}$ \\
\hline & $F A_{3}$ & $\begin{array}{l}\text { Gross floor area density of } \\
\text { building }\end{array}$ & $\begin{array}{l}\text { This factor will affect the heat dissipation per unit } \\
\text { area of land }\end{array}$ & $\begin{array}{l}\text { Statistics, measurement, } \\
\text { calculation }\end{array}$ \\
\hline & $F A_{4}$ & Greenbelt area & $\begin{array}{l}\text { This factor has a minor climate regulation effect } \\
\text { and helps to cool the environment }\end{array}$ & $\begin{array}{l}\text { Statistics, measurement, } \\
\text { calculation }\end{array}$ \\
\hline & $F A_{5}$ & Average number of floors & $\begin{array}{l}\text { This factor will affect the day-time heat island } \\
\text { effect }\end{array}$ & $\begin{array}{l}\text { Statistics, measurement, } \\
\text { calculation }\end{array}$ \\
\hline \multirow{5}{*}{$\begin{array}{l}\text { Influencing } \\
\text { factors of } \\
\text { land } \\
\text { attribute }\end{array}$} & $F A_{6}$ & Location & $\begin{array}{l}\text { This factor will affect the surface heat } \\
\text { distribution in the city }\end{array}$ & Statistics \\
\hline & $F A_{7}$ & $\begin{array}{l}\text { Water vapor content of } \\
\text { atmosphere }\end{array}$ & This factor will affect the urban heat island effect & $\begin{array}{l}\text { Statistics, measurement, } \\
\text { calculation }\end{array}$ \\
\hline & $F A_{8}$ & $\begin{array}{c}\text { Greenbelt area of surrounding } \\
\text { areas }\end{array}$ & $\begin{array}{l}\text { This factor has a minor climate regulation effect } \\
\text { and helps to cool the environment }\end{array}$ & $\begin{array}{l}\text { Statistics, measurement, } \\
\text { calculation }\end{array}$ \\
\hline & $F A 9$ & $\begin{array}{l}\text { Building density of } \\
\text { surrounding areas }\end{array}$ & $\begin{array}{l}\text { This factor will affect the heat dissipation of the } \\
\text { regional land }\end{array}$ & $\begin{array}{l}\text { Statistics, measurement, } \\
\text { calculation }\end{array}$ \\
\hline & $F A_{10}$ & $\begin{array}{l}\text { Gross floor area density of } \\
\text { building of surrounding areas }\end{array}$ & $\begin{array}{l}\text { This factor will affect the heat dissipation per unit } \\
\text { area of the regional land }\end{array}$ & $\begin{array}{l}\text { Statistics, measurement, } \\
\text { calculation }\end{array}$ \\
\hline
\end{tabular}

Table 2. Correlation analysis of influencing factors of urban thermal environment

\begin{tabular}{|c|c|c|c|c|c|c|c|c|c|c|}
\hline & $F A_{1}$ & $F A_{2}$ & $F A_{3}$ & $F A_{4}$ & $F A_{5}$ & $F A_{6}$ & $F_{4}$ & $F A_{8}$ & $F A_{9}$ & $F A_{10}$ \\
\hline$F A_{1}$ & 1 & & & & & & & & & \\
\hline$F A_{2}$ & 0.836 & 1 & & & & & & & & \\
\hline$F A_{3}$ & 0.849 & 1.146 & 1 & & & & & & & \\
\hline$F A_{4}$ & -0.043 & -0.036 & -0.038 & 1 & & & & & & \\
\hline$F A_{5}$ & 0.009 & 0.026 & -0.726 & -0.035 & 1 & & & & & \\
\hline$F A_{6}$ & 0.442 & 0.769 & -0.856 & -0.848 & 0.618 & 1 & & & & \\
\hline$F A_{7}$ & 0.187 & 0.247 & -0.645 & -0.035 & 0.732 & 0.094 & 1 & & & \\
\hline$F A_{8}$ & -0.135 & -0.039 & -0.931 & -0.076 & 0.736 & -0.031 & -0.135 & 1 & & \\
\hline$F A 9$ & -0.038 & -0.387 & -0.038 & -0.025 & 0.472 & -0.032 & -0.037 & -0.068 & 1 & \\
\hline$F A_{10}$ & 0.014 & 0.578 & 0.247 & 0.065 & 0.893 & 0.456 & 0.045 & 0.042 & 0.642 & 1 \\
\hline
\end{tabular}


Using the One-Way ANOVA of SPSS software, the 10 influencing factors of urban thermal environment were subject to multiple comparisons, and the significance of difference between any two influencing factors was obtained. According to the Table 2, among the 45 comparison combinations of the 10 influencing factors, the values of the significance of difference of 16 pairs were less than 0.05 , therefore, there're significant differences between these 16 pairs of influencing factors, wherein the greenbelt area factor and the greenbelt area of surrounding areas factor are significantly different from other influencing factors, and the location factor is not significantly different from other influencing factors.

In this study, the L1B data of MODIS downloaded from the website of NASA was adopted to perform LST retrieval of the target city. Assume $B R_{j}$ represents the apparent radiance obtained from the DN (Digital Number) calibration of MODIS band image; $\varphi_{j}$ represents the effective center wavelength; wherein the value of the effective center wavelength of the 31 st band takes 11.21; the value of the effective center wavelength of the 32 nd band takes 12.22; the spectral constants $\mathrm{P}^{\prime}$ and $\mathrm{P}^{\prime \prime}$ take the values of $1.18 \times 10^{-16} \mathrm{~W} \cdot \mathrm{m}^{2}$ and $1.44 \mu \mathrm{m} \cdot \mathrm{K}$. Then the brightness temperature can be calculated by the inverse function of the Plank function shown in Eq. (1):

$$
B R_{j}=\frac{P^{\prime \prime}}{\phi_{j} \ln \left(1+\frac{P^{\prime}}{\phi_{j}^{5} X_{j}}\right)}
$$

The pixels of MODIS images can be divided into two types according to the surface emissivity: land, and water body. For the target city, the surface emissivity of water body can be equivalent to the average value of the emissivity of water body in the two bands. Assume $\sigma_{B Z}$ and $\sigma_{T L}$ represent the surface emissivity of the vegetation and the surface emissivity of bare land of the target city; $\eta_{B Z}$ and $\eta_{T L}$ represent the corresponding temperature ratio of the two; $V_{B Z}$ represents the pixel vegetation coverage that can be estimated by the vegetation index, then the surface emissivity of land can be estimated by Eq. (2):

$$
\sigma=V_{B Z} \eta_{B Z} \sigma_{B Z}+\left(1-V_{B Z}\right) \eta_{T L} \sigma_{T L}
$$

Assume $N_{B Z}$ represents the vegetation coverage index of vegetation-covered pixels, its value takes $0.65 ; N_{T L}$ represents the vegetation coverage index of bare land-covered pixels, its value takes $0.5 ; A_{M-1}$ and $A_{M-2}$ represent the reflectivity of MODIS 1 and 2 bands, then $V_{B Z}$ can be expressed as:

$$
V_{B Z}=\left[\left(N-N_{T L}\right) /\left(N_{B Z}-N_{T L}\right)\right]^{2}
$$

where, $N$ is the total vegetation coverage index, and it can be calculated by Eq. (4):

$$
N D V I=\left(A_{M-2}-A_{M-1}\right) /\left(A_{M-2}+A_{M-1}\right)
$$

As the main cause of the fluctuations in the atmospheric transmittance $\delta$, the water vapor content of atmosphere $M_{A M}$ also needs to be accurately estimated. Assume the constant $\gamma$ takes the value of 0.02 , and $\theta$ takes the value of 0.6321 . First, $M_{A M}$ is estimated based on the data of MODIS 2 and 19 bands. Assume $\xi_{M-1}$ and $\xi_{M-2}$ represent the reflectivity of the corresponding bands, then there is:

$$
M_{A M}=\left[\left(\gamma-\ln \left(\frac{\xi_{M-2}}{\xi_{M-1}}\right)\right) / \theta\right]^{2}
$$

Eqns. (6)-(7) give the relationship between $\delta$ and $M_{A M}$ :

$$
\begin{gathered}
\delta_{b-1}=2.89798-1.88366 \mathrm{e}^{-\left(M_{A M} /-21.22704\right)} \\
\delta_{b-2}=-3.59289+4.60414 \mathrm{e}^{-\left(M_{A M} /-32.70639\right)}
\end{gathered}
$$

In the same way, the $\delta$ and $M_{A M}$ of MODIS 31 and 32 bands can be calculated. Figure 1 shows the measurement results of LST of different land utilization patterns.

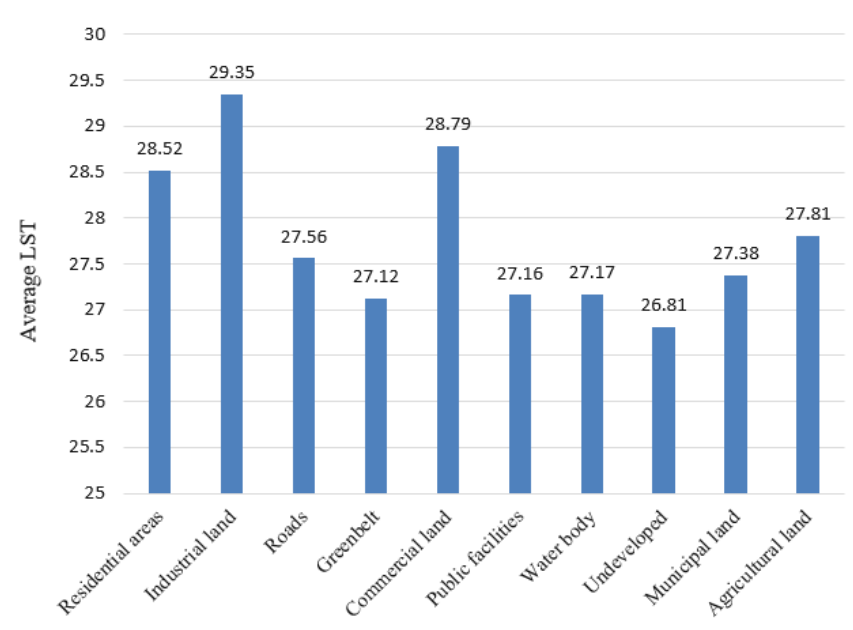

Figure 1. LST measurement results of different land utilization patterns

\section{MLR ANALYSIS}

\subsection{Construction of MLR model}

To figure out the law of numerical changes between the influencing factors, namely the degree of impact a certain factor is affected by other factors, this paper used MLR to describe the mathematical relationship between influencing factors of urban thermal environment. In the regression analysis, LST can be taken as the dependent variable, other influencing factors can be taken as independent variables, and all of them can be random variables.

Assume $b$ is a numerically observable LST variable which is affected by factors $a_{1}, a_{2}, \ldots, a_{v}$, namely the explanatory variables or dependent variables, and factors a1, a2,...,av are explanatory variables or dependent variables. Assume $\rho_{0}, \rho_{1}, \ldots$, $\rho_{v}$ are $\mathrm{v}+1$ parameters to be estimated, and $\eta$ is an unmeasurable random error that conforms to $M\left(0, \phi^{2}\right)$, the MLR model can be expressed by Eq. (8):

$$
b=\rho_{0}+\rho_{1} a_{1}+\ldots+\rho_{v} a_{v}+\eta
$$

Then, multiple regression equations were established to deal with the actual problem of the relationship between influencing factors, the unknown influencing factor parameters $\rho_{0}, \rho_{1}, \ldots, \rho_{v}$ need to be estimated. Assume independent monitoring of the urban thermal environment has been carried out for $m$ times, then $m$ sets of LST measurement 
sample data $\left(a_{j 1}, a_{j 2}, \ldots, a_{j v} ; b_{j}\right)$ could be obtained, where $j=1,2, \ldots$, $n$, and each set of data satisfies the equations shown in Eq. (9):

$$
\left\{\begin{array}{c}
b_{1}=\rho_{0}+\rho_{1} a_{11}+\rho_{2} a_{12}+\ldots+\rho_{v} a_{1 v}+\eta_{1} \\
b_{2}=\rho_{0}+\rho_{1} a_{21}+\alpha_{2} a_{22}+\ldots+\rho_{v} a_{2 v}+\eta_{2} \\
\ldots \ldots \ldots \ldots \\
b_{m}=\rho_{0}+\rho_{1} x_{m 1}+\rho_{2} a_{n 2}+\ldots+\rho_{v} a_{m v}+\eta_{m}
\end{array}\right.
$$

where, $\eta_{1}, \eta_{2}, \ldots, \eta_{m}$ all conform to $M\left(0, \phi^{2}\right)$ and are independent of each other. The above equations can be simplified to the matrix form of Eq. (10):

$$
B=A \rho+\eta
$$

where, $\quad B=\left(b_{1} b_{2}, \ldots, b_{m}\right)^{T}, \quad \rho=\left(\rho_{0}, \rho_{1}, \ldots, \rho_{v}\right)^{T}, \quad \eta=\left(\eta_{1}, \eta_{2}, \ldots, \eta_{m}\right)^{T}$. Assume $J_{m}$ is the m-order unit matrix, then $\eta$ here conforms to $M_{m}\left(0, \phi^{2} J_{m}\right)$. The $m \times(v+1)$-order data matrix or design matrix $A$ in the equation can be expressed as:

$$
A=\left\lfloor\begin{array}{ccccc}
1 & a_{11} & a_{12} & \ldots & a_{1 v} \\
1 & a_{21} & a_{22} & \ldots & a_{2 v} \\
\vdots & \vdots & \vdots & & \vdots \\
1 & a_{m 1} & a_{m 2} & \ldots & a_{m v}
\end{array}\right\rfloor
$$

$A$ is a column non-singular matrix, that is, it satisfies $\operatorname{rank}(A)=v+1$.

\subsection{Least-squares estimation of parameters}

In this paper, the unknown influencing factor parameters $\rho_{0}$, $\rho_{1}, \ldots, \rho_{v}$ were estimated by the least-square method, that is, a suitable $\rho=\left(\rho_{0}, \rho_{1}, \ldots, \rho_{v}\right)^{T}$ was constructed to minimize the sum of squared errors (SSE) shown in Eq. (12).

$$
\begin{aligned}
W(\rho) & \hat{=} \sum_{j=1}^{m} \eta_{j}^{2}=\vec{\eta}^{T} \vec{\eta}=(B-A Y)^{T}(B-A Y) \\
& =\sum_{j=1}^{m}\left(b_{j}-\rho_{0}-\rho_{1} a_{j 1}-\rho_{2} a_{j 2}-\ldots \rho_{v} a_{j v}\right)^{2}
\end{aligned}
$$

Assume $\rho^{\prime}{ }_{j}$ represents the least-squares estimate of the $j$-th influencing factor parameter $\rho_{j}$, the partial derivative solution method shown as Eq. (13) can be used to obtain the solution that can minimize the SSE:

$$
\left\{\begin{array}{l}
\frac{\partial W\left(\rho^{\prime}\right)}{\partial \rho_{0}}=-2 \sum_{j=1}^{m}\left(b_{j}-\rho_{0}^{\prime}-\rho_{1}^{\prime} a_{j 1}-\rho_{2}^{\prime} a_{j 2}-\ldots-\rho_{v}^{\prime} a_{j v}\right)=0 \\
\frac{\partial W\left(\rho^{\prime}\right)}{\partial \rho_{1}}=-2 \sum_{j=1}^{m}\left(b_{j}-\rho_{0}^{\prime}-\rho_{1}^{\prime} a_{j 1}-\rho_{2}^{\prime} a_{j 2}-\ldots-\rho_{v}^{\prime} a_{j v}\right) a_{j 1}=0 \\
\frac{\partial W\left(\rho^{\prime}\right)}{\partial \rho_{l}}=-2 \sum_{j=1}^{m}\left(b_{i}-\rho_{0}^{\prime}-\rho_{1}^{\prime} a_{j 1}-\rho_{2}^{\prime} a_{j 2}-\ldots-\rho_{v}^{\prime} a_{j v}\right) a_{j l}=0 \\
\frac{\partial W\left(\rho^{\prime}\right)}{\partial \rho_{v}}=-2 \sum_{j=1}^{m}\left(b_{j}-\rho_{0}^{\prime}-\rho_{1}^{\prime} a_{j 1}-\rho_{2}^{\prime} a_{j 2}-\ldots-\rho_{v}^{\prime} a_{j v}\right) a_{j v}=0
\end{array}\right.
$$

Above equations were sorted into a matrix form shown in Eq. (14):

$$
A^{T} A \rho^{\prime}=A^{T} B
$$

If we assume $D(A)=v+1$, then there is $D\left(A^{T} A\right)=D(A)=v+1$, and the inverse matrix of $\left(A^{T} A\right)$ exists. By solving Eq. (14), the least square estimate $\rho^{\prime}$ of the influencing factor parameters could be obtained:

$$
\rho^{\prime}=\left(A^{T} A\right)^{-1}=A^{T} B
$$

By substituting the observed values of each group of factors $a_{1}, a_{2}, \ldots, a_{v}$ into the empirical regression equation $b^{*}=\rho_{0}{ }^{\prime}+\rho_{1}{ }^{\prime} a_{1}+\rho_{2}{ }^{\prime} a_{2}+\ldots+\rho_{v}{ }^{\prime} a_{v}$, the estimate of influencing factor $b$ shown as Equation 16 can be obtained:

$$
B^{*}=\left(b_{1}^{*}, b_{1}^{*}, \ldots, b_{v}^{*}\right)^{2}=A \rho^{\prime}
$$

Eq. (17) gives the corresponding residual vector

$$
\begin{aligned}
& \vec{r}=B-B^{*}=B-A \rho^{\prime} \\
& =\left[J_{m}-A\left(A^{T} A\right)^{-1} A^{T}\right] B=\left(J_{m}-G\right) B
\end{aligned}
$$

Combining with the calculation results of $\vec{r}$, the required residual sum of squares can be obtained from Eq. (18):

$$
\vec{r}^{T} \vec{r}=B^{T}\left(J_{m}-G\right) B=B^{T} B-\rho^{\prime T} A^{T} B
$$

Assume $\varphi^{\prime 2}=\frac{1}{m-v-1} \vec{r}^{T} \vec{r}$ is an unbiased estimate of $\phi^{2}$, $\operatorname{Error}(B)=A \rho$ and it satisfies that $\left(J_{m}-G\right) A$ is 0 , then there is:

$$
\begin{aligned}
& \operatorname{Error}\left(\vec{r}^{T} \vec{r}\right)=\operatorname{Error}\left\{\operatorname{tr}\left[\eta^{T}\left(J_{m}-G\right) \vec{\eta}\right]\right\} \\
& \quad=\operatorname{tr}\left[\left(J_{m}-G\right) \operatorname{Error}\left(\vec{\eta} \vec{\eta}^{T}\right)\right] \\
& \quad=\varphi^{2} \operatorname{tr}\left[J_{m}-A\left(A^{T} A\right)^{-1} A^{T}\right] \\
& \quad=\varphi^{2}\left\{m-\operatorname{tr}\left[\left(A^{T} A\right)^{-1} A^{T} A\right]\right\} \\
& \quad=\varphi^{2}(m-v-1)
\end{aligned}
$$

\section{BP NEURAL NETWORK MODEL CONSTRUCTION AND EXECUTION PROCESS}

Based on the MLR results, this paper constructed a BP neural network to predict the quality evaluation of urban thermal environment based on the scores of influencing factors, then the effect was verified by two algorithms to make the result more convincing. For a constructed three-layer BP neural network model, assume $A=\left(a_{1}, a_{2}, \ldots, a_{j}, \ldots a_{m}\right)^{T}$ represents the input data, $B=\left(b_{1}, b_{2}, \ldots b_{i}, \ldots b_{m}\right)^{T}$ represents the output of the hidden layer, $P=\left(p_{1}, p_{2}, . . p_{l .,}, . . p_{k}\right)^{T}$ represents the output of the output layer, $h=\left(h_{1}, h_{2}, \ldots h_{j}, \ldots h_{k}\right)^{T}$ represents the expected output of the network, and $Q_{i}$ represents the weight vector corresponding to the $i$-th neuron in the hidden layer, then, the connection weight matrix between the input layer and the hidden layer can be written as $Q=\left(Q_{1}, Q_{2}, \ldots, Q_{j}, \ldots Q_{n}\right)$. Similarly, assume $\omega_{l}$ represents the weight vector corresponding to the $l$-th neuron in the output layer; then the weight matrix from the hidden layer to the output layer can be 
expressed as $W=\left(\omega_{1}, \omega_{2}, \ldots \omega_{l}, \ldots \omega_{k}\right)^{T}$. The output of the output layer of the neural network can be calculated by Eq. (20):

$$
p_{l}=g\left(\sum_{i=0}^{n} \omega_{i l} b_{i}\right), l=1,2, \ldots, k
$$

The output of the hidden layer can be calculated by Eq. (21):

$$
b_{i}=g\left(\sum_{j=0}^{n} \omega_{j i} a_{j}\right), i=1,2, \ldots, n
$$

The activation function $g(x)$ of the neural network was defined as the unipolar Sigmoid function shown as Eq. (22):

$$
g(a)=\frac{1}{1+e^{-a}}
$$

Taking the derivative of Eq. (22), we can get:

$$
g^{\prime}(a)=g(a)[1-g(a)]
$$

Eqns. (20)-(22) are the mathematical model of the constructed BP neural network, its output error can be defined by Eq. (24):

$$
\text { Error }=\frac{1}{2}(h-P)^{2}=\frac{1}{2} \sum_{l=1}^{k}\left(h_{l}-p_{l}\right)^{2}
$$
(25):

The output error of the hidden layer can be defined by Eq.

$$
\text { Error }=\frac{1}{2} \sum_{l=1}^{k}\left[h_{l}-g\left(\sum_{i=0}^{n} \omega_{i l} b_{i}\right)\right]^{2}
$$

Similarly, the output error of the input layer can be defined by Eq. (26):

$$
\text { Error }=\frac{1}{2} \sum_{l=1}^{k}\left\{h_{l}-g\left[\sum_{i=0}^{n} \omega_{i l} g\left(\sum_{i=0}^{n} q_{j i} a_{i}\right)\right]\right\}^{2}
$$

According to Eqns. (24)-(26), the overall error of the network can be reduced by correcting the weights $\omega_{i l}$ and $q_{j i}$ of each layer that are directly related to the output error of each layer. Assume $\mu$ represents the learning speed of the network, first, the weight and the gradient of the error can be connected by Eqns. (27) and (28):

$$
\begin{gathered}
\Delta \omega_{i l}=-\mu \frac{\partial E r r o r}{\partial \omega_{i l}}, i=0,1,2, \ldots n, l=1,2, \ldots, k \\
\Delta q_{j i}=-\mu \frac{\partial E r r o r}{\partial q_{j i}}, j=0,1,2, \ldots m, i=1,2, \ldots n
\end{gathered}
$$

The negative sign in the equations means gradient descent. According to the equations, the size of the adjusted weight is proportional to the gradient of the error. Then, adjust the weight value of Eq. (27):

$$
\Delta \omega_{i l}=-\mu \frac{\partial E r r o r}{\partial \omega_{i l}}=-\mu \frac{\partial E r r o r}{\partial\left(\sum_{i=0}^{n} \omega_{i l} b_{i}\right)} \frac{\partial\left(\sum_{i=0}^{n} \omega_{i l} b_{i}\right)}{\partial \omega_{i l}}
$$

Similarly, the weight of Eq. (28) can be adjusted to:

$$
\Delta q_{j i}=-\mu \frac{\partial \text { Error }}{\partial q_{j i}}=-\mu \frac{\partial \text { Error }}{\partial\left(\sum_{j=0}^{n} \omega_{j i} a_{j}\right)} \frac{\partial\left(\sum_{j=0}^{n} \omega_{j i} a_{j}\right)}{\partial q_{j i}}
$$

The error signal of the output layer was defined as:

$$
\zeta_{l}^{p}=-\frac{\partial E r r o r}{\partial\left(\sum_{i=0}^{n} \omega_{i l} b_{i}\right)}
$$

Similarly, the error signal of the hidden layer can be described as:

$$
\zeta_{i}^{b}=-\frac{\partial \text { Error }}{\partial\left(\sum_{j=0}^{n} \omega_{j i} a_{j}\right)}
$$

Combining Eq. (20) and Eq. (31), there is:

$$
\Delta \omega_{i l}=\mu \zeta_{l}^{p} a_{j}
$$

Combining Eq. (21) and Eq. (32), there is:

$$
\Delta q_{j i}=\mu \zeta_{i}^{b} a_{j}
$$

According to Eq. (33) and Eq. (34), by calculating $\zeta^{p}$ and $\zeta_{i}^{b}$, the adjusted weight of each layer of the neural network could be obtained; then, based on the adjusted values, we can further differentiate $\zeta^{p}$ and $\zeta_{i}^{b}$. The error signal $\zeta_{l}^{p}$ of the output layer can be expanded as:

$$
\xi_{l}^{p}=-\frac{\partial E r r o r}{\partial p_{l}} \frac{\partial p_{l}}{\partial\left(\sum_{i=0}^{n} \omega_{i l} b_{i}\right)}=-\frac{\partial E r r o r}{\partial p_{l}} g^{\prime}\left(\sum_{i=0}^{n} \omega_{i l} b_{i}\right)
$$

The error signal $\zeta_{i}$ of the hidden layer can be expanded as:

$$
\xi_{i}^{b}=-\frac{\partial E r r o r}{\partial b_{i}} \frac{\partial b_{i}}{\partial\left(\sum_{j=0}^{n} \omega_{j i} a_{j}\right)}=-\frac{\partial E r r o r}{\partial b_{i}} g^{\prime}\left(\sum_{j=0}^{n} \omega_{j i} a_{j}\right)
$$

Finding the partial derivative of the output error of the input layer shown as Eq. (24), we can get:

$$
\frac{\partial \text { Error }}{\partial p_{l}}=-\left(h_{l}-p_{l}\right)
$$

Finding the partial derivative of the output error of the hidden layer shown as Eq. (25), we can have:

$$
\frac{\partial \text { Error }}{\partial b_{i}}=-\sum_{l=1}^{k}\left(h_{l}-p_{l}\right) g^{\prime}\left(\sum_{j=0}^{n} \omega_{j i} a_{j}\right) \omega_{i l}
$$


Combining Eqns. (23), (35), (36), (37), and (38), the final derivation equations of error signals $\zeta^{p}$ and $\zeta_{i}^{b}$ can be obtained as:

$$
\begin{gathered}
\zeta_{l}^{p}=\left(h_{l}-p_{l}\right) p_{l}\left(1-p_{l}\right) \\
\zeta_{i}^{b}=\left[\sum_{l-1}^{k}\left(h_{l}-p_{l}\right) g^{\prime}\left(\sum_{i=0}^{n} \omega_{i l} b_{i}\right) \omega_{i l}\right] g^{\prime}\left(\sum_{j=0}^{n} \omega_{j i} a_{j}\right) \\
=\left(\sum_{l-1}^{k} \zeta_{l}^{p} \omega_{i l}\right) b_{j}\left(1-b_{i}\right)
\end{gathered}
$$

Combining Eqns. (33), (34), (39), and (40), the equations of the final adjusted weight of the network can be obtained as:

$$
\left\{\begin{array}{l}
\Delta \omega_{i l}=\mu \zeta_{l}^{p} b_{i}=\mu\left(h_{l}-p_{l}\right) p_{l}\left(1-p_{l}\right) b_{i} \\
\Delta q_{j i}=\mu \zeta_{i}^{b} a_{j}=\mu\left(\sum_{l-1}^{k} \zeta_{l}^{p} \omega_{i l}\right) b_{j}\left(1-b_{i}\right) a_{j}
\end{array}\right.
$$

\section{EXPERIMENTAL RESULTS AND ANALYSIS}

In order to solve the problem of the lack of real-time LST data as a comparison reference in the verification of LST retrieval results, this paper collected the mean, maximum and minimum values of daily $0 \mathrm{~cm}$ LST data from local weather stations and compared them with the LST retrieval results of the target city calculated based on MODIS data. Table 3 shows the comparison results. It can be seen from the table that the LST retrieval results can reflect the local LST to a certain extent, and they could be taken as the conditions for subsequent research.

The urban thermal environment is greatly affected by the development modes of urban residential areas. Table 4 and
Table 5 respectively show the results of overall regression and mean regression of the thermal environment in urban residential areas. The regression fitting coefficient $R$ value and the variance test $p$ value are 0.471 and 0.001 , indicating that the regression fitting is at a medium level, all selected influencing factors have significant impact, wherein factors $F A_{2}, F A_{3}, F A_{9}, F A_{10}$ are positively correlated with LST, indicating that the LST of residential areas increases with the increase of the building density of surrounding areas; other factors are negatively correlated with LST, indicating that the LST decreases with the increase of the average number of floors, the water vapor content of atmosphere, and the greenbelt area.

Similar to the situations in urban residential areas, the greenbelt area and the building density are also the main influencing factors of the thermal environment in urban commercial areas. Table 6 and Table 7 respectively show the results of overall regression and mean regression of thermal environment in urban commercial areas. According to the tables, $F A_{2}$ and $F A_{3}$ are positively correlated with LST, $F A_{4}$ is negatively correlated with LST, indicating that for urban commercial areas, the lower the building density, and larger the greenbelt area, the lower the LST. Properly creating more open space and greenbelt in urban commercial areas will help improve the thermal environment of urban commercial areas.

For urban industrial areas, the impact degrees of the main influencing factors of thermal environment are: $F A_{2}$ has a low impact degree, $F A_{3}$ has a high impact degree, and $F A_{5}$ has a relatively high impact degree. Table 8 and Table 9 respectively show the results of overall regression and mean regression of the thermal environment in urban industrial areas. According to the tables, $F A_{2}$ and $F A_{3}$ are positively correlated with LST, $F A_{4}$ and $F A_{5}$ are negatively correlated with LST, indicating that increasing greenbelt area and average number of floors and decreasing building density can help improving the thermal environment in urban industrial areas.

\begin{tabular}{|c|c|c|c|c|c|}
\hline \multirow{2}{*}{ Code of influencing factor } & \multirow{2}{*}{$\begin{array}{c}\text { Standardized coefficient } \\
\text { Beta value }\end{array}$} & \multicolumn{2}{|c|}{ Unstandardized coefficient } & \multirow{2}{*}{ t-test } & \multirow{2}{*}{ Significance of difference. } \\
\hline & & $\mathrm{B}$ value & Mean standard deviation & & \\
\hline$F A_{1}$ & -10.435 & -5.721 & 0.101 & -2.365 & 0.000 \\
\hline$F A_{2}$ & 0.135 & 2.831 & 0.632 & 3.782 & 0.000 \\
\hline$F A_{3}$ & 0.125 & 0.029 & 0.016 & 2.465 & 0.007 \\
\hline $\mathrm{FA}_{4}$ & -0.043 & -0.035 & 0.001 & -2.317 & 0.005 \\
\hline$F A_{5}$ & -0.176 & -0.002 & 0.001 & -7.129 & 0.001 \\
\hline$F A_{6}$ & -0.275 & -0.236 & 0.053 & -4.561 & 0.000 \\
\hline $\mathrm{FA}_{7}$ & -0.169 & -0.736 & 0.198 & -4.362 & 0.001 \\
\hline$F A_{8}$ & -0.158 & -0.073 & 0.023 & -3.794 & 0.000 \\
\hline$F A_{9}$ & 0.237 & 2.684 & 0.589 & 4.275 & 0.001 \\
\hline$F A_{10}$ & 0.092 & 0.168 & 0.073 & 2.031 & 0.045 \\
\hline
\end{tabular}

Table 3. Comparison results of LST retrieval

\begin{tabular}{cccccc}
\hline Time period & Station altitude & Maximum & Minimum & Mean & Retrieval result \\
\hline Day time & 835.6 & 28.20 & 17.67 & 22.93 & 28.65 \\
Night time & 835.6 & 21.75 & 15.31 & 18.53 & 16.27 \\
\hline
\end{tabular}

\begin{tabular}{|c|c|c|c|c|c|}
\hline \multirow{2}{*}{ Code of influencing factor } & \multirow{2}{*}{$\begin{array}{c}\text { Standardized coefficient } \\
\text { Beta value }\end{array}$} & \multicolumn{2}{|c|}{ Unstandardized coefficient } & \multirow{2}{*}{ t-test } & \multirow{2}{*}{ Significance of difference. } \\
\hline & & $B$ value & Mean standard deviation & & \\
\hline$F A_{2}$ & 0.275 & 13.88 & 2.215 & 2.825 & 0.001 \\
\hline$F A_{3}$ & 0.264 & 11.421 & 3.342 & 3.367 & 0.000 \\
\hline $\mathrm{FA}_{4}$ & -0.531 & -2.534 & 0.127 & -9.372 & 0.000 \\
\hline
\end{tabular}

Table 4. Multiple linear overall regression results of thermal environment in urban residential areas

Table 5. Multiple linear mean regression results of thermal environment in urban residential areas 
Table 6. Multiple linear overall regression results of thermal environment in urban commercial areas

\begin{tabular}{|c|c|c|c|c|c|}
\hline \multirow{2}{*}{ Code of influencing factor } & \multirow{2}{*}{$\begin{array}{c}\text { Standardized coefficient } \\
\text { Beta value }\end{array}$} & \multicolumn{2}{|c|}{ Unstandardized coefficient } & \multirow{2}{*}{ t-test } & \multirow{2}{*}{ Significance of difference. } \\
\hline & & $B$ value & Mean standard deviation & & \\
\hline$F A_{2}$ & 0.137 & 3.451 & 0.576 & 4.315 & 0.000 \\
\hline$F A_{3}$ & 0.275 & 0.352 & 0.061 & 5.123 & 0.000 \\
\hline $\mathrm{FA}_{4}$ & -0.166 & -3.159 & 0.468 & -5.111 & 0.001 \\
\hline$F A_{5}$ & -0.315 & -0.072 & 0.007 & -7.831 & 0.000 \\
\hline
\end{tabular}

Table 7. Multiple linear mean regression results of thermal environment in urban commercial areas

\begin{tabular}{|c|c|c|c|c|c|}
\hline \multirow{2}{*}{ Code of influencing factor } & \multirow{2}{*}{$\begin{array}{c}\text { Standardized coefficient } \\
\text { Beta value }\end{array}$} & \multicolumn{2}{|c|}{ Unstandardized coefficient } & \multirow[b]{2}{*}{ t-test } & \multirow{2}{*}{ Significance of difference } \\
\hline & & B value & Mean standard deviation & & \\
\hline$F A_{2}$ & 0.521 & 3.451 & 0.436 & 6.341 & 0.000 \\
\hline$F A_{3}$ & 0.611 & 0.627 & 0.073 & 7.253 & 0.000 \\
\hline $\mathrm{FA}_{4}$ & -0.534 & -21.596 & 3.159 & -7.156 & 0.001 \\
\hline
\end{tabular}

Table 8. Multiple linear overall regression results of thermal environment in urban industrial areas

\begin{tabular}{|c|c|c|c|c|c|}
\hline \multirow{2}{*}{ Code of influencing factor } & \multirow{2}{*}{$\begin{array}{c}\text { Standardized coefficient } \\
\text { Beta value }\end{array}$} & \multicolumn{2}{|c|}{ Unstandardized coefficient } & \multirow{2}{*}{ t-test } & \multirow{2}{*}{ Significance of difference } \\
\hline & & B value & Mean standard deviation & & \\
\hline$F A_{2}$ & 0.235 & 2.753 & 0.239 & 8.156 & 0.000 \\
\hline$F A_{3}$ & -0.211 & -0.234 & 0.034 & -6.145 & 0.000 \\
\hline $\mathrm{FA}_{4}$ & 0.123 & 0.001 & 0.000 & 5.623 & 0.000 \\
\hline$F A_{5}$ & -0.236 & -0.569 & 0.093 & -6.057 & 0.000 \\
\hline$F A_{6}$ & 0.234 & 3.952 & 0.641 & 5.443 & 0.000 \\
\hline
\end{tabular}

Table 9. Multiple linear mean regression results of thermal environment in urban industrial areas

\begin{tabular}{|c|c|c|c|c|c|}
\hline \multirow{2}{*}{ Code of influencing factor } & \multirow{2}{*}{$\begin{array}{c}\text { Standardized coefficient } \\
\text { Beta value } \\
\end{array}$} & \multicolumn{2}{|c|}{ Unstandardized coefficient } & \multirow{2}{*}{ t-test } & \multirow{2}{*}{ Significance of difference } \\
\hline & & $B$ value & Mean standard deviation & & \\
\hline$F A_{2}$ & -0.532 & -23.756 & 3.376 & -8.356 & 0.000 \\
\hline$F A_{3}$ & -0.437 & -0.614 & 0.135 & -5.364 & 0.000 \\
\hline $\mathrm{FA}_{4}$ & 0.235 & 7.145 & 2.635 & 2.239 & 0.001 \\
\hline
\end{tabular}

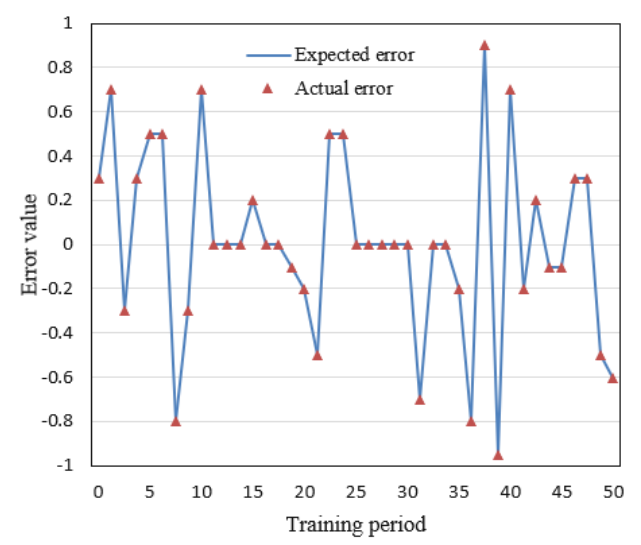

(a)

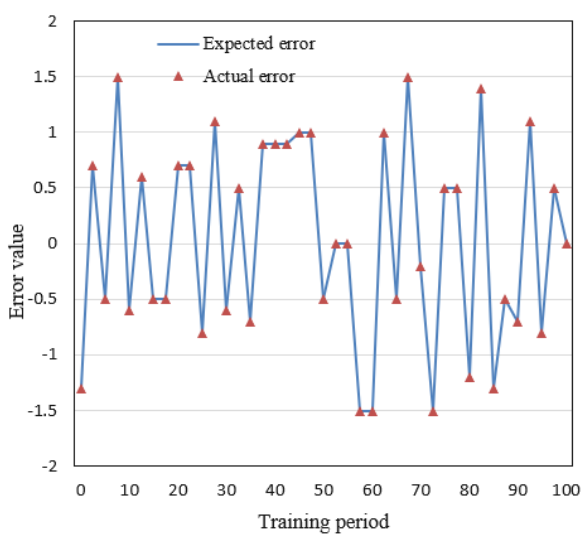

(b)

Figure 2. Training error of the constructed neural network

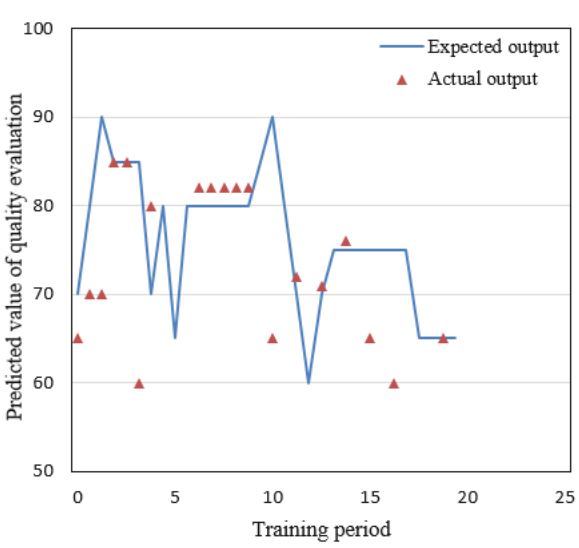

(a)

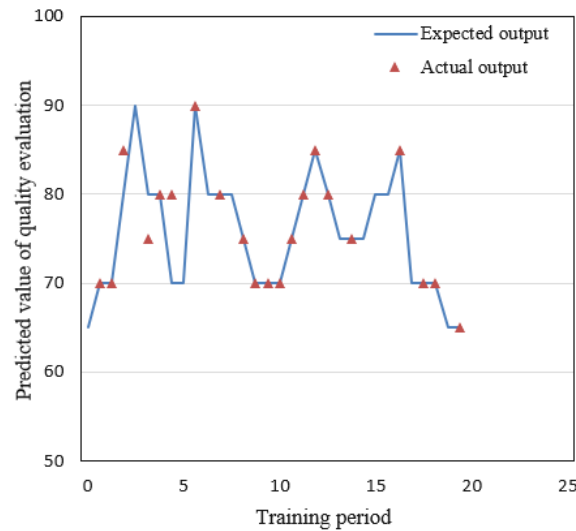

(b)

Figure 3. Test results of the constructed neural network 
To verify the effectiveness of the predication made by the constructed BP neural network on the quality evaluation of urban thermal environment, this study conducted quality evaluation on a test set containing 15 samples. The node numbers of the input layer, hidden layer, and output layer of the network were set to 5,11 , and 1 ; the activation functions were respectively tansig, purelin function, and trainlm function, and the error range was set to 0.005 . Figure 2 shows the comparison of network training error and expected error of the network before and after weight adjustment; Figure 3 shows the network test results before and after weight adjustment. In the neural network prediction, after the specific city's LST values were input and the quantitative values of the influencing factors were compared, it's obtained that among all test samples, the number of misjudgments was reduced from 7 to 2 , and the accuracy rate reached $86.7 \%$.

\section{CONCLUSION}

This paper extracted 10 influencing factors of urban thermal environment and gave their influence, and then performed LST retrieval of a target city. The experimental results verified that the LST retrieval results can reflect the local LST to a certain extent, and they could be taken as the conditions for subsequent research. Based on a constructed MLR model, this study explored the law of the numerical changes of influencing factors of urban thermal environment, and experiments obtained the multiple linear overall regression and mean regression results of the thermal environment in urban residential areas, commercial areas, and industrial areas, and a few strategies for improving urban thermal environment were proposed. At last, this paper constructed a BP neural network to predict the quality evaluation of urban thermal environment, the experimental results proved that the network training error and the test error before and after weight adjustment were relatively low, which had verified that the prediction of the quality evaluation of urban thermal environment was effective.

\section{REFERENCES}

[1] Nasir, D.S., Pantua, C.A.J., Zhou, B., Vital, B., Calautit, J., Hughes, B. (2021). Numerical analysis of an urban road pavement solar collector (U-RPSC) for heat island mitigation: Impact on the urban environment. Renewable Energy, 164: 618-641. https://doi.org/10.1016/j.renene.2020.07.107

[2] Park, C.Y., Yoon, E.J., Lee, D.K., Thorne, J.H. (2020). Integrating four radiant heat load mitigation strategies is an efficient intervention to improve human health in urban environments. Science of The Total Environment, 698:

134259

https://doi.org/10.1016/j.scitotenv.2019.134259

[3] Revesz, A., Chaer, I., Thompson, J., Mavroulidou, M., Gunn, M., Maidment, G. (2019). Modelling of heat energy recovery potential from underground railways with nearby vertical ground heat exchangers in an urban environment. Applied Thermal Engineering, 147: 10591069.

https://doi.org/10.1016/j.applthermaleng.2018.10.118

[4] Saito, K., Said, I., Shinozaki, M. (2017). Evidence-based neighborhood greening and concomitant improvement of urban heat environment in the context of a world heritage
site-Malacca, Malaysia. Computers, Environment and Urban Systems, 64: 356-372. https://doi.org/10.1016/j.compenvurbsys.2017.04.003

[5] Salata, F., Golasi, I., Petitti, D., de Lieto Vollaro, E., Coppi, M., de Lieto Vollaro, A. (2017). Relating microclimate, human thermal comfort and health during heat waves: An analysis of heat island mitigation strategies through a case study in an urban outdoor environment. Sustainable Cities and Society, 30: 79-96. https://doi.org/10.1016/j.scs.2017.01.006

[6] Swamy, G., Nagendra, S.S., Schlink, U. (2017). Urban heat island (UHI) influence on secondary pollutant formation in a tropical humid environment. Journal of the Air \& Waste Management Association, 67(10): 10801091. 10.1080/10962247.2017.1325417

[7] Hatvani-Kovacs, G., Belusko, M., Skinner, N., Pockett, J., Boland, J. (2016). Heat stress risk and resilience in the urban environment. Sustainable Cities and Society, 26: 278-288. https://doi.org/10.1016/j.scs.2016.06.019

[8] Nie, W.S., Sun, T., Ni, G.H. (2014). Spatiotemporal characteristics of anthropogenic heat in an urban environment: A case study of Tsinghua Campus. Building and Environment, 82: 675-686. https://doi.org/10.1016/j.buildenv.2014.10.011

[9] Malings, C., Pozzi, M., Klima, K., Bergés, M., Bou-Zeid, E., Ramamurthy, P. (2018). Surface heat assessment for developed environments: Optimizing urban temperature monitoring. Building and Environment, 141: 143-154. https://doi.org/10.1016/j.buildenv.2018.05.059

[10] Pascal, M., Laaidi, K., Beaudeau, P. (2019). Relevance of green, shaded environments in the prevention of adverse effects on health from heat and air pollution in urban areas. Sante Publique, (HS1), 1: 197-205.

[11] Ramos, A., Chatzopoulou, M.A., Guarracino, I., Freeman, J., Markides, C.N. (2017). Hybrid photovoltaic-thermal solar systems for combined heating, cooling and power provision in the urban environment. Energy Conversion and Management, 150: 838-850. https://doi.org/10.1016/j.enconman.2017.03.024

[12] Takebayashi, H., Moriyama, M. (2012). Relationships between the properties of an urban street canyon and its radiant environment: Introduction of appropriate urban heat island mitigation technologies. Solar Energy, 86(9): 2255-2262. https://doi.org/10.1016/j.solener.2012.04.019

[13] Howard, B.N., Modi, V. (2012). Potential for distributed combined heat and power in an urban environment. In Energy Sustainability, 44816: 209-215. https://doi.org/10.1115/ES2012-91452

[14] Verstina, N., Evseev, E. (2017). Technical-andeconomic aspects of the analysis of the heating systems maintenance in the conditions of urban environment. In MATEC Web of Conferences, 106: 08090. https://doi.org/10.1051/matecconf/201710608090

[15] Rozbicka, K., Majewski, G., Rogula-Kozłowska, W., Rozbicki, T. (2020). Tropospheric ozone assessment in urban environment-Warsaw case study of selected heat waves. Journal of Atmospheric and Solar-Terrestrial Physics, 209:

105418. https://doi.org/10.1016/j.jastp.2020.105418

[16] Guilbert, D., Caluwaerts, S., Calle, K., Van Den Bossche, N., Cnudde, V., De Kock, T. (2019). Impact of the urban heat island on freeze-thaw risk of natural stone in the built environment, a case study in Ghent, Belgium. 
Science of the Total Environment, 677: 9-18. https://doi.org/10.1016/j.scitotenv.2019.04.344

[17] Palou, F.S., Mahalov, A. (2019). Summer-and Wintertime Variations of the Surface and Near-Surface Urban Heat Island in a Semiarid Environment. Weather and Forecasting, 34(6): 1849-1865. https://doi.org/10.1175/WAF-D-19-0054.1

[18] Chatterjee, S., Khan, A., Dinda, A., Mithun, S., Khatun, R., Akbari, H., Wang, Y. (2019). Simulating micro-scale thermal interactions in different building environments for mitigating urban heat islands. Science of the Total Environment, 663:

$610-631$ https://doi.org/10.1016/j.scitotenv.2019.01.299

[19] Kurbatskiy, A., Kurbatskaya, L. (2015). Numerical model of the urban heat island in a calm and stably stratified environment. In 21 st International Symposium Atmospheric and Ocean Optics: Atmospheric Physics, 9680: 968058. https://doi.org/10.1117/12.2203154

[20] Revesz, A., Chaer, I., Thompson, J., Mavroulidou, M., Gunn, M., Maidment, G. (2016). Ground source heat pumps and their interactions with underground railway tunnels in an urban environment: A review. Applied Thermal Engineering, 93: 147-154. https://doi.org/10.1016/j.applthermaleng.2015.09.011

[21] Coseo, P., Larsen, L. (2019). Accurate characterization of land cover in urban environments: Determining the importance of including obscured impervious surfaces in urban heat island models. Atmosphere, 10(6): 347. https://doi.org/10.3390/atmos10060347

[22] Pan, J. (2015). Analysis of human factors on urban heat island and simulation of urban thermal environment in Lanzhou city, China. Journal of Applied Remote Sensing, 9(1): 095999. https://doi.org/10.1117/1.JRS.9.095999

[23] Malings, C., Pozzi, M., Klima, K., Bergés, M., Bou-Zeid, E., Ramamurthy, P. (2017). Surface heat assessment for developed environments: Probabilistic urban temperature modeling. Computers, Environment and Urban Systems, 66: 53-64. https://doi.org/10.1016/j.compenvurbsys.2017.07.006

[24] Sabatino, S.D., Barbano, F., Brattich, E., Pulvirenti, B. (2020). The multiple-scale nature of urban heat island and its footprint on air quality in real urban environment. Atmosphere, $11(11)$ : 1186. https://doi.org/10.3390/atmos11111186

[25] Guo, G., Wu, Z., Chen, Y. (2020). Evaluation of spatially heterogeneous driving forces of the urban heat environment based on a regression tree model. Sustainable Cities and Society, 54: 101960. https://doi.org/10.1016/j.scs.2019.101960 